\title{
Sexual Behaviour and Abuse of Drugs Among Urban Teenagers in Lagos
}

\author{
Molobe Ikenna Daniel ${ }^{1,2,3,4}$ \\ ${ }^{1}$ Unified Initiative for a Drug-Free Nigeria, Lagos, Nigeria \\ ${ }^{2}$ World Federation Against Drugs (WFAD), Stockholm, Sweden \\ ${ }^{3}$ Foundation for a Drug-Free World (FDFW), Los Angeles, USA \\ ${ }^{4}$ International Substance Abuse and Addiction Coalition (ISAAC), UK
}

Email address:

danike1@yahoo.com

\section{To cite this article:}

Molobe Ikenna Daniel. Sexual Behaviour and Abuse of Drugs Among Urban Teenagers in Lagos. Science Journal of Public Health. Special Issue: Addiction and Substance Abuse. Vol. 4, No. 5-1, 2016, pp. 17-19. doi: 10.11648/j.sjph.s.2016040501.14

Received: July 2, 2016; Accepted: July 8, 2016; Published: September 3, 2016

\begin{abstract}
Sexual dependence and abuse of drugs including the abuse of sexual stimulants and abortion drugs has been observed among the urban teens. This finding was observed through personal encounters and follow-up investigations while working with teenagers in selected communities of Lagos State. Many youngsters are engaging in risky sexual activities while abusing both prescribed drugs and psychotropic substances to enhance their sexual performance. Most of these sexual activities have resulted to high risk of teenage pregnancy abortion with misuse and abuse of drugs and substances to prevent pregnancy or induce the abortion. In most cases, the male partner responsible contributes or influences the use of these drugs and substances for the prevention of pregnancy or induced abortion. This study was carried out in Lagos Urban community which revealed the risk sexual behavioral activities engaged by youngsters.
\end{abstract}

Keyword: Sexual Behavior, Teens, Drugs and Substance Abuse, Abortion, Lagos

\section{Introduction}

Children and adolescents need accurate and comprehensive education about sexuality to practice healthy sexual behavior while growing up or becoming adult (Blanc, 1988). Early exposure to sexual activity may lead to health and social problems, such as unwanted pregnancy and sexually transmitted infections (STIs), including human immunodeficiency virus infection and acquired immunodeficiency syndrome (HIV/AIDS). Sexuality education should be integrated into the confidential and longitudinal relationship the parents and guardians develop with children through the education children acquire in the school, and the society must be aware of the children's own attitudes, beliefs, and values so that their effectiveness in discussing sexuality in the community setting is not limited (Cohen, 2000).

Children most likely to engage in earlier sexual activity include children with social, behavioral, or emotional problems; those from low-income families; victims of physical and sexual abuse; and children in families with marital discord and low levels of parental supervision (JHU, 2004). It has been found that adolescents also engage themselves in sexual intercourse when they are idol and when adults are not around. Sexual activeness increases when they have had their first experience. Magazines, movies and internet pornography have contributed to these risky sexual behaviors. Risky sexual behaviors, defined as having multiple partners or having sex with strangers, are also associated with lack of information and depression, and can lead to dropping out of school, homelessness (running away or being thrown out of the home), and substance abuse (IPPF, 2015). However, these adolescents have fear of disclosure which is one of the major reasons for having missed care they believed that they needed.

Recent urban community study by the author has found a recurring incidence of sexual activity in adolescents in the urban Lagos State. However, initiation to sexual intercourse 
during adolescence was found to remain the practice in the study community. This has also resulted to high abuse of drugs and substances to stimulate sexual arousal and performance, and the abuse of drugs to prevent pregnancy and removing of unwanted pregnancy among these adolescents.

\section{Methodology}

This report was a compilation from investigative study with the urban teenagers carried out in selected urban communities in Lagos through one-on-one interactions with the teenagers, community observations, and reports received. Questionnaire was also administered in a school during a sexuality education program to assess the students' knowledge and attitude in adolescent reproductive health.

\section{Findings and Discussions}

Adolescent between the ages of $12-17$ in the urban community of Lagos has been discovered to be indulging in risky sexual activities. These teenagers out of ignorance and misinformation by their peers have been abusing various drugs and substances while engaging in sexual activities, and some of them have become addicted to sexual intercourse. Some of the sexual activities have also resulted to pregnancy among the girl partners who have also committed unsafe abortion due to unwanted pregnancy. The study also revealed that the victims use all kinds of local and harmful substances to induce abortion when pregnant, thereby exposing themselves to health hazards while some have dropped out from the school. The study revealed the following as described below.

Teens between the ages of $12-17$ were indiscriminately having sexual intercourse with same-sex or opposite sex, and from interactions with some of these teens they own up that they have found it difficult to abstain from having sex since their first initiation and experience and always look for sexual satisfaction almost every day. After having a chat with most of the affected teens, it was also found that some of these teens have been sexually abused during their childhood.

Some of the sexual acts among these teens have resulted to unwanted pregnancy including recording STI, and as a result, the affected teens have abused drugs to remove the pregnancy or treat the sexual infections. These teens have used substances such as local concoctions, washing blue and psychotropic substances to induce abortion. Most of the abortion by abuse of drugs is influence by the male partner who provides these drugs or substances. It was also found that these teen surf on the internet to discover abortion pills and have been able to obtain these pills from the pharmacy shops without doctor's prescription. The most abortion pills that have been found used by these teens are Mifepristone and Misoprostol. Some of the affected teens that have committed an unsafe abortion are experiencing post abortion syndrome while passing through physical and emotional trauma thereby resort to drugs and substance abuse, and some had educational setback or have dropped out from the school. Emotional and psychological disturbance that follows after the abortion known as Post-abortion traumatic effects and disturbances are depression, isolation, drug abuse and attempt to commit suicide (Cook, 2010). These post abortion syndrome can cause mental ill health, educational setback and drop out from school.

Also, as a result of misinformation these teens disclosed that they always take antibiotics or mixture of substances before sex in order to prevent pregnancy as a form of contraceptives. The use of all kinds of drugs and substances either to prevent pregnancy or terminate pregnancy affects the body functionary system which may lead to infertility and damage to vital organs in the body. Some attempt to abort a baby by use of psychotropic medications and other substances which failed has led to birth of deformed baby. Such babies are abandoned in the hospital or thrown away. Some of them died and some are picked up and sent to motherless baby home.

In the case of sexual infections, antibiotics and herbal mixtures are frequently misused and abused by these teens on self-medication without disclosing to their parents or guardians. They are misinformed by their peers to use these drugs.

The use of sexual stimulants drugs especially among the teen boys is becoming rampant. It was found that they use drugs such as Viagra, Marijuana and local herbal substances mostly to stimulate or boost their sexual performance. They purchase these drugs through street drug hawkers. The street drug vendors claimed that the drugs help to also enlarge the male organ in order to convince these teen to buy these drugs. Tramadol is widely abused by these teens to delay ejaculation and prolong intercourse. This Tramadol is mostly abused without knowledge of the effect and health implications of the use. The teen boys also believe that alcohol can also stimulate their sexual performance and thus abuse alcohol a lot. However, excess consumption of alcoholic drinks initially may stimulate one but depresses the body system and reduces self-control or causes impaired judgement which can lead to unprotected sex and also affects the body system (Cook, 2010).

It was also observed that teens have developed a strong network of sex engagements on social media using most especially Facebook account to connect to others and negotiate for physical visits or arrangement for sexual intercourse. In this process they also discuss or exchange information on various drugs and substances they can use to stimulate their sexual urge. In the course of this study "Date Rape Drugs" most especially Rohypnol was also discovered to be sometimes used by the teen boys when they invite their teen mate through their social media interaction. Cases have been recounted where group of teens connected with female on internet and invited her for the first time and drug her drink and had sex with her. The use of sedative which is becoming more common is slipped into female drink in order to cause drowsiness and sometimes short memory loss. As a result, she may be sexually assaulted or agree to have sex, 
and most of these sexual act is unprotected. Generally, "Date Rape Drug" can be in form of powder, pill, capsule or liquid form and have little or no taste, color or odor (Howard et al, 2003).

In a survey carried out by the author in a secondary school in Lagos to access the student's knowledge, attitude and practice in adolescent reproductive health, the result showed that $45.5 \%$ of the students have engaged in sex and out of those that have engaged in sex, $40 \%$ of them used condom for protection, while $60 \%$ do not use protection. $58.5 \%$ of the student has received sexuality education from their parents and $42.5 \%$ have not received sexuality education from their parents. The age bracket of the secondary school students assessed was $9-19$ years.

\section{Conclusion and Recommendation}

The primary aim of this study is to reveal the state of sexual behavior, drugs and substance abuse among the urban teen in order to provide basis for further research and also to inform stakeholders to enable them design out of school and school-based sexuality education to help the school children build a foundation as they mature into sexually healthy adults. The information on this research will assist stakeholders understand the view of the teens in sexuality, and the stakeholders can provide them with information and skills for taking care of their sexual health, and help them make sound decisions now and in the future. Additionally, out of school and school-based interventions can provide opportunities for individual risk assessments or targeted preventive counseling.

In the Youth Risk Behavior Surveillance survey conducted by the Centers for Disease Control and Prevention in 1997, almost all $(>90 \%)$ adolescents reported having received human immunodeficiency virus (HIV) prevention education in school, have been observed discussing HIV and acquired immunodeficiency syndrome (AIDS) with their peers, parents or guardians. Though, the content of such discussions may not provide complete information.

Teens are experimental and have engaged in abuse and misuse of drugs and substances while experimenting in sexual activities. Drugs and substance abuse is detrimental to health, and should be avoided while education is very importance for the children to get the right information. Sexual Reproductive Health education and interventions should be coupled with drugs and substance abuse prevention to reduce the risky behaviors associated.

\section{References}

[1] Blanc Ann K. and Ann A. Way (1988). Sexual Behaviour, Contraceptive Knowledge and Use in Studies in Family Planning Vol. 29, No. 2.
[2] CDC (1977). Youth Risk Behavior Surveillance survey, Centers for Disease Control and Prevention, USA

[3] Cohen, S.I. and Burger M., (2000). Partnering: A new approach to sexual and reproductive health. New York, United Nations Population Fund (UNFPA), Technical Paper No. 3:17, $181 \mathrm{p}$.

[4] Cook, P.A. et al (2010). Contributions of alcohol use to teenage pregnancy and sexually transmitted infection rates. North West Public Health Observatory, Centre for Public Health, Liverpool John Moores University.

[5] EMCDDA (2011). Survey result: youth attitudes to drugs. Drugnet Europe. Newsletter of the European Monitoring Centre for Drugs and Drug Addiction, Lisbon, Portugal, July September 2011, P1.

[6] EMCDDA (2014). Eurobarometer survey result: young people and drugs. Drugnet Europe. Newsletter of the European Monitoring Centre for Drugs and Drug Addiction, Lisbon, Portugal, July - September 2014, P1.

[7] Ford Foundation (2001). Experiences in Building Cross-Field Partnerships for Sexuality and Reproductive Health. Ford Foundation Publication, New York, USA.

[8] Ford Foundation (2001). Sexuality and Reproductive Health; Strategies for Programming. Ford Foundation Publication, New York, USA.

[9] Howard J \& Stubbs M. (2003). Youth Substance Use. A selfdirected learning package for staff of Ted Noffs Foundation, Sydney, Australia.

[10] Howard J., Stubbs M., Clancey G., \& Arcuri A., (2003). Understanding and Managing Challenging Behaviours. A self-directed learning package. Ted Noffs Foundation, Sydney, Australia.

[11] International Planned Parenthood Federation. Alcohol, Drug and Sex. https://www.plannedparenthood.org/teens/sex/sexalcohol-and-other-drugs

[12] John Hopkins University (2004). Preventing Risk to our Future, HIV/AIDS and other Sexual Transmitted Infections for Adolescents, JHU/CCP \& UNICEF, USA.

[13] Johnston, L.D., O’Malley P.M., Bechman J.G., and Schulenberg J.E., (2011). Monitoring the future. National results on adolescent drug use - Overview of key findings, 2010. Ann arbor: Institute for Social Research, The University of Michigan. www.monitoringthefuture.org/pubs/monographs/mtfoverview2010.pdf

[14] Matias J., and Olszewski D., (2011). Monitoring the future: adolescent drug use in the US. Drugnet Europe. Newsletter of the European Monitoring Centre for Drugs and Drug Addiction, Lisbon, Portugal, EMCDDA April - June 2001, P2. 